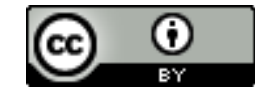

Esta obra está sob o direito de Licença Creative Commons Atribuição 4.0 Internacional.

\title{
A INTERDISCIPLINARIDADE NO PROCESSO DE ENSINO-APRENDIZAGEM ${ }^{1}$
}

\author{
Maria Tatiane Santos Santana \\ Thiago Mecenas Silva do Amor Divino ${ }^{2}$
}

\section{RESUMO}

Este estudo busca discutir a interdisciplinaridade como um movimento contemporâneo presente nas dimensões da epistemologia e da pedagogia que vem marcando o rompimento com a visão cartesiana e mecanicista da área educacional e, ao mesmo tempo assumindo uma concepção mais integradora, dialética e totalizadora na construção do conhecimento e da prática pedagógica. Inicialmente, faz-se uma breve apresentação da origem da interdisciplinaridade, discutem-se aspectos de sua conceituação e suas implicações no campo das diferentes ciências contemporâneas para então apresentar a interdisciplinaridade como um importante fenômeno de articulação do processo de ensino e aprendizagem. A argumentação apresentada no texto busca destacar que o movimento da interdisciplinaridade pode transformar profundamente a qualidade da educação escolar por intermédio de seus processos de ensino.

Palavras-chave: Educação. Ensino-Aprendizagem. Interdisciplinaridade.

\section{RESUMEM}

Este estudio busca discutir la interdisciplinariedad como un movimiento contemporáneo presente en las dimensiones de la epistemología y la pedagogía que ha marcado la ruptura con la visión cartesiana y mecanicista del área educativa y, al mismo tiempo, asumiendo un concepto más integrador, dialéctico y totalizador en la construcción del conocimiento. y práctica pedagógica. Inicialmente, se realiza una breve presentación del origen de la interdisciplinariedad, se discuten aspectos de su conceptualización y sus implicaciones en el campo de las diferentes ciencias contemporáneas, y luego, se presenta la interdisciplinariedad como un fenómeno importante de articulación del proceso de enseñanza y aprendizaje. El argumento presentado en el texto busca resaltar que el movimiento interdisciplinario puede transformar profundamente la calidad de la educación escolar a través de sus procesos de enseñanza.

Palabras clave: Educación. Enseñanza-Aprendizaje. Interdisciplinariedad.

\footnotetext{
1 santanatatiane2011@ hotmail.com

2 thiagomecenas@ hotmail.com
} 


\section{INTRODUÇÃO}

A interdisciplinaridade é discutida como um movimento atual na dimensão do conhecimento e da pedagogia. A socialização do conhecimento é uma necessidade na produção e no campo educativo e vem sendo discutida principalmente por autores que pesquisam sobre as teorias curriculares e as mudanças pedagógicas. É preciso saber que a interdisciplinaridade se apresenta de forma integradora, entremeando e retratando o mundo atual globalizado, facilitando $\mathrm{o}$ processo de produção e socializando a aprendizagem.

Neste estudo se procura construir um entendimento quanto aos principais objetivos a serem revelados e atingidos por meio da implementação de práticas interdisciplinares no ensino aprendizagem. Procura-se compreender formas de organização de um trabalho interdisciplinar escolar que contextualize conhecimentos, informações, sistematização e resultados.

A interdisciplinaridade leva à contextualização e articulação do conhecimento produzido e vivenciado pelo homem. Essa mudança tão necessária no processo ensino- aprendizagem será realidade quando se materializar em atitudes, num novo modo de pensar, fazendo parte da organização curricular, modificando as metodologias de ensino e se tornando parte da formação dos profissionais da educação.

\section{Origem e conceitos de interdisciplinaridade}

A interdisciplinaridade, como um enfoque teórico-metodológico ou gnosiológico, como a denomina Gadotti (2004), surge na segunda metade do século passado, em resposta a uma necessidade verificada principalmente nos campos das ciências humanas e da educação que é superar a fragmentação da especialização do conhecimento, o que poderia ser causado por uma epistemologia de tendência positivista em cujas raízes de acordo com Gadotti (2004) estão o empirismo, o naturalismo e o mecanicismo científico do início da modernidade.

Sobretudo pela influência dos trabalhos de grandes pensadores modernos como Galileu, Bacon, Descartes, Newton, Darwin e outros, as ciências foram sendo divididas e, por isso, especializando-se. Organizadas, de modo geral, sob a influência das correntes de pensamento naturalista e mecanicista elas buscavam, já a partir da Renascença, ao que já inferia Godaman (1979), construir uma concepção mais científica de mundo. A interdisciplinaridade, como um movimento contemporâneo que emerge na perspectiva da dialogicidade e da integração das ciências e do conhecimento, ela vem 
buscando romper com o caráter de hiperespecialização e com fragmentação dos saberes organizados nas ciências, mas ao mesmo tempo se fundamentando nelas refletindo na educação em diversos períodos no Brasil.

Para Goldman (1979) "[...] existe um olhar interdisciplinar sobre a realidade e permite que entendamos melhor a relação entre seu todo e as partes que a constituem." (GOLDMAN, 1979, p. 3-25), Para ele, apenas o modo dialético de pensar, fundado na historicidade, poderia favorecer maior integração entre as ciências. Nesse sentido, o materialismo histórico e dialético resolveu em parte o problema da fragmentação do conhecimento quando colocou a historicidade e as leis do movimento dialético da realidade como fundamentos para todas as ciências. Desde então, o conceito de interdisciplinaridade vem sendo discutido nos diferentes âmbitos científicos e muito fortemente na educação. Sem dúvida, tanto as formulações filosóficas do materialismo histórico e dialético quanto as proposições pedagógicas das teorias críticas trouxeram contribuições importantes para esse novo enfoque epistemológico.

É no campo das ciências humanas e sociais que a interdisciplinaridade aparece com maior força. A preocupação com uma visão mais totalizadora da realidade cognoscível e com a consequente dialogicidade das ciências foi objeto de estudo primeiramente na filosofia, posteriormente nas ciências sociais e mais recentemente na epistemologia pedagógica. Isso nos trabalhos como o de Kapp (1961), Durand (1991), Snow (1959) e Gusdorf (1967) são alguns exemplos desse movimento.

Goldman (1979) destaca que, inicialmente, a interdisciplinaridade aparece como preocupação humanista, além da preocupação com as ciências. Desde então, parece que todas as correntes de pensamento se ocuparam com a questão da interdisciplinaridade; nisto, de acordo com Goldman (1979), a teologia fenomenológica encontrou nesse conceito uma chave para o diálogo entre Igreja e mundo; o existencialismo buscou dar às ciências uma cara mais humana; a epistemologia buscou desvendar o processo de construção do conhecimento e garantir maior integração entre as ciências, e o materialismo histórico e dialético buscou, no método indutivo-dedutivo indutivo, uma via para integrar parte e todo, ou partir do todo para as partes.

Consoante à pedagogia, ao que infere Gadotti (1993), Georges Gusdorf lançou na década de 60 um projeto interdisciplinar para as ciências humanas apresentado à Organização das Nações Unidas para a Educação, a Ciência e a Cultura e (UNESCO). A obra La parole 
(1953) é considerada muito importante para entender a interdisciplinaridade. $\mathrm{O}$ projeto de interdisciplinaridade nas ciências passou de uma fase filosófica (humanista), de definição e explicitação terminológica, na década de 70, para uma segunda fase, (mais científica), de discussão do seu lugar nas ciências humanas e na educação a partir da década de 80.

Gadotti (1993) ressalta que atualmente, no plano teórico, se busca fundar a interdisciplinaridade na ética e na antropologia, ao mesmo tempo em que, no plano prático, surgem projetos que reivindicam uma visão interdisciplinar, sobretudo no campo do ensino e do currículo. No Brasil, o conceito de interdisciplinaridade chegou pelo estudo da obra de Georges Gusdorf e posteriormente da obra de Piaget. O primeiro autor influenciou o pensamento de Hilton Japiassu no campo da epistemologia e o de Ivani Fazenda no campo da educação.

Quanto à definição de conceitos, ou de um conceito, para interdisciplinaridade, tudo parece estar ainda em construção. Qualquer demanda por uma definição unívoca e definitiva deve ser a princípio rejeitada, por se tratar de proposta que inevitavelmente está sendo construída a partir das culturas disciplinares existentes; e por encontrar o limite objetivo de sua abrangência conceitual; o que significa concebê-la em uma óptica disciplinar. Ou, como afirma Leis (2005): “[...] a tarefa de procurar definições finais para a interdisciplinaridade não seria algo propriamente interdisciplinar, senão disciplinar" (LEIS, 2005, p. 7).

Para Leis (2005), na medida em que não existe uma definição única possível para esse conceito, senão muitas, tantas quantas sejam as experiências interdisciplinares em curso no campo do conhecimento, entende-se que se deva evitar procurar definições abstratas de interdisciplinaridade. Os conhecimentos disciplinares são paradigmáticos ao que infere Kuhn (1989), porém não os são, os interdisciplinares. Neste aspecto, a história da interdisciplinaridade se confunde com a dinâmica viva do conhecimento. Isso não pode ser dito quanto a história das disciplinas, que congelam de forma paradigmática o conhecimento alcançado em determinado momento histórico, defendendo-se de qualquer abordagem alternativa em uma guerra de trincheiras.

O que se pode afirmar no campo conceitual é que a interdisciplinaridade será sempre uma reação alternativa à abordagem disciplinar normalizadora, seja no ensino ou na pesquisa, e associada aos diversos objetos de estudo. Independentemente da definição que cada autor assuma, a interdisciplinaridade está sempre situada no campo onde se pensa a possibilidade de superar a fragmentação das ciências e dos 
conhecimentos produzidos por elas e onde simultaneamente se exprime a resistência sobre um saber parcelado.

Brasil (2016), no documento curricular da educação Brasileira, a Base Nacional Comum curricular, corrobora algo que desde 1976 já era um pressuposto para a experiência, a troca interdisciplinar no fazer pedagógico, diz respeito o que Japiassu (1976) informava a interdisciplinaridade se caracterizar intensidade das trocas entre os especialistas e pelo grau de integração real das disciplinas no interior de um mesmo projeto. Brasil (2014) corrobora em uma das 10 competências do documento ela ser uma ação educativa, de gestão educacional para se

[...] decidir sobre formas de organização interdisciplinar dos componentes curriculares e fortalecer a competência pedagógica das equipes escolares para adotar estratégias mais dinâmicas, interativas e colaborativas em relação à gestão do ensino e da aprendizagem. (BRASIL, 2016, p. 16).

Para tanto, é imprescindível a complementaridade dos métodos, dos conceitos, das estruturas e dos axiomas sobre os quais se fundam as diversas práticas pedagógicas das disciplinas científicas.

Outro ponto de discussão da BNCC, em Brasil (206) condiz com o acesso ao conhecimento e informação dispostos para os alunos, o que Japiassu (1976) postula como amplitude ou bases de conhecimento; e nisto o fazer, a tarefa, a integração com os campos de experiência, citado por Japiassu (1976) como profundidade, ou requisitos para o desenvolvimento de tarefas, por fim as competências, resultados finais esperados ao final de cada aula, projeto, etc. o que Japiassu (1976) destaca como sendo a síntese integradora, ou conciliação de todo o processo e de todo o processo integrador.

As abordagens teóricas apresentadas pelos vários autores esclarecem que o pensamento e as práticas interdisciplinares, tanto nas ciências em geral quanto na educação, compreendem as disciplinas como um espaço de organização, sistematização e socialização dos conhecimentos parciais produzidos no âmbito de uma ciência para fins de ensino e pesquisa com etapas de investigação, produção e socialização. Nisto se propõe uma profunda revisão de pensamento sistêmico educacional, que deve caminhar no sentido da intensificação do diálogo, das trocas, da integração conceitual e metodológica nos diferentes campos do saber, corroborados na BNCC como campos de experiência, e, asseverados por Japiassu (1976) como um empreendimento interdisciplinar incorporado os resultados de várias especialidades, com instrumentos e técnicas metodológicas, fazendo uso dos 
esquemas conceituais e das análises que se encontram nos diversos ramos do saber,(disciplinas, convergindo para uma mediação, um ponte entre conteúdos, na BNCC denominados de objetos de aprendizagem, e objetivos, denominados por Brasil (2016) de competências a serem desenvolvidas pelos alunos, sempre a buscar resultados positivos.

\section{A interdisciplinaridade no âmbito escolar}

Os estudos e pesquisas que buscam fundamentar a introdução de práticas interdisciplinares no âmbito escolar existem características específicas destinadas a atingir objetivos educacionais diferentes. Dessa forma, a interdisciplinaridade escolar necessita estar fundamentada em pressupostos que indiquem uma orientação epistemológica do processo a permitir um delineamento dos objetivos que os educandos venham a desenvolver.

Uma proposta de prática interdisciplinar como ação educativa escolar é apresentada por Santomé (1998), que defende a construção coletiva de unidades didáticas integradas num determinado número de disciplinas, ou mesmo áreas do conhecimento, que elaborariam uma unidade temática em torno de uma situação problemática -, que exigiria a contribuição de diferentes saberes durante um intervalo de tempo relativamente curto. É praticamente o formato organizacional dos objetos do conhecimento descritos na BNCC.

Essa proposta destina-se a iniciar um processo cujo objetivo maior é a elaboração de um currículo integrado, que busca abranger os conteúdos de um determinado número de disciplinas ou áreas de conhecimentos durante um período considerável, pelo menos de um ano letivo, e deve ser planejado de tal forma que não gere lacunas importantes nos conteúdos a serem assimilados pelos estudantes. (SANTOMÉ, 1998, p. 222).

Esse ponto de vista é defendido frente ao argumento de que, em qualquer nível educacional, a coerência do planejamento curricular não se demostra perceptível aos alunos e, aos professores dificultando qualquer forma de integração entre os conteúdos das diferentes disciplinas.

De acordo com Santomé (1998), a elaboração de unidades didáticas integradas, se constitui no desenvolvimento de alguns passos que, em linhas gerais, podem ser descritos como: diagnóstico prévio; determinação das metas educacionais; seleção do tópico a pesquisar; elaboração de um plano de pesquisa; seleção de recursos e estratégias didáticas e avaliação dos estudantes e da unidade didática.

Uma unidade didática integrada não pretende eliminar ou diminuir a importância 
das disciplinas, mas busca promover um entendimento dos conteúdos disciplinares em uma perspectiva mais ampla, não necessariamente abrangendo todas as disciplinas ou áreas do conhecimento, mas articulando-as de tal forma que as abordagens disciplinares estabeleçam vínculos que proporcionem o desenvolvimento de ações mais complexas.

Outra forma de entendimento da interdisciplinaridade é esboçada por Fourez et.al. (1997), que estabelecem uma fundamentação para o desenvolvimento de uma proposta interdisciplinar no ensino de ciências e de matemática, objetivando promover uma alfabetização científica e tecnológica, que, no sentido atribuído por (FOUREZ, 1997, p. 23), consiste em "[...] divulgar conhecimentos suficientes para a população de maneira que as decisões dos técnicos possam ser suficientemente compreendidas e também controladas democraticamente".

A justificativa para o desenvolvimento das práticas interdisciplinares é fundamentada de forma mais destacada no questionamento quanto à eficácia das disciplinas do ensino de ciências e de matemática em relação à introdução dos alunos na discussão de questões científicas e tecnológicas, sobretudo relacionadas à necessidade de ensiná-los a utilizar o conhecimento científico e tecnológico em seu cotidiano, seja em relação a questões sociais, individuais ou políticas.

A interdisciplinaridade é descrita por Fourez, (1997), em um sentido restrito, como:

[...] a construção de representações do mundo que se encontram estruturadas e organizadas em função de um projeto humano (ou de um problema a resolver), em um contexto específico e para destinatários específicos, apelando a diversas disciplinas, objetivando chegar a um resultado original não dependente das disciplinas de origem. (FOUREZ, et. al. 1997, p. 106-107).

Considerando esse entendimento em torno da interdisciplinaridade e defendendo que esta, no âmbito escolar, não se coloca apenas como uma questão de ordem didática, mas situada em função de princípios epistemológicos, ressalta-se que os professores assumam uma forma de representação operacional que possa dar sentido a essas práticas tão largamente mencionadas na BNCC.

Fourez (1997) apresenta, então, um procedimento metodológico denominado de ilhas interdisciplinares de racionalidade, que orienta as atividades no interior de um trabalho interdisciplinar se constituindo num modelo simplificado, integrado à várias disciplinas nas quais é “[...] considerado adequado, que utiliza conhecimentos provenientes de várias disciplinas e, adicionalmente, dos saberes 
presentes na vida cotidiana, indispensáveis ante as práticas concretas." (FOUREZ, 1997, p. 109).

Esse procedimento leva a considerar que a interdisciplinaridade é analisada de um ponto de vista restrito e localizado, direcionado a abordar problemas concretos ou noções específicas, buscando estabelecer elos de relação entre o conhecimento científico e tecnológico presente em situações concretas do cotidiano.

De acordo com Fourez (1997), um aspecto relevante diz respeito à formação dos professores, pois estes últimos foram e são formados em uma perspectiva disciplinar. Assim, uma proposta que busque alterar essa forma de trabalho de maneira extrema, direcionando-a para uma prática transdisciplinar, dá origem a fortes reações contrárias e, como a proposta necessita de uma articulação coletiva, pode se tornar inviável.

Existe um entendimento diferenciado em relação à adoção de práticas interdisciplinares é encontrado em Batista e Salvi (2006), indicando que a prática educativa escolar necessita atribuir maior importância epistemológica ao caráter pluralístico contemporâneo. Considerando a manutenção de uma estrutura disciplinar, as autoras propõem que, em momentos específicos do trabalho pedagógico, insiram-se momentos interdisciplinares como uma forma de relacionar, articular e integrar os conhecimentos disciplinares no processo de ensino e de aprendizagem, promovendo uma educação científica na qual o educando adquira competências para interpretar a complexidade do mundo atual.

Batista e Salvi (2006) dão atenção à adoção de enfoques que fundamentem a implementação de práticas interdisciplinares na perspectiva de construção do conhecimento durante o processo de ensino e de aprendizagem, apresentando contrapontos em relação às concepções que buscam aliar a interdisciplinaridade às finalidades unicamente sociais.

Esse entendimento deriva de uma análise quanto ao significado relativo da realidade, à inconclusividade e relativismo presentes nas explicações e análises científicas e à presença de elementos contextuais e plurais, buscando superar os limites impostos por posturas deterministas e simplificadoras que dificultam uma compreensão mais profunda da realidade. (BATISTA; SALVI, 2006, p.154).

$\mathrm{Na}$ visão das autoras, a interdisciplinaridade no ensino não significaria a elaboração de um currículo interdisciplinar com a inserção de momentos específicos e ampla aprendizagem, pois a realização de um trabalho interdisciplinar se localizaria no interior de um processo que prevê e mantém a adoção de enfoques disciplinares, 
articulados coerentemente entre $\mathrm{o}$ conhecimento disciplinar e interdisciplinar. Compreenderia a construção do conhecimento "[...] levando em consideração as suas concepções prévias, e [levando-o] a atingir uma alfabetização científica que contemple um recorte epistemológico fundamentado na Pósmodernidade e no pensamento complexo." (BATISTA; SALVI, 2006, p. 155. Grifo das autoras). Neste aspecto as análises seriam de certa complexidade, mas interrelacionadas e integradoras das partes como o significado do todo. Essa proposta pode se colocar como uma alternativa com potencial de proporcionar a superação da excessiva especialização dos conteúdos presentes nas disciplinas escolares.

Adicionalmente, tal proposta direciona os objetivos educacionais para

\section{CONSIDERAÇÕES FINAIS}

Fora compreendido que houve mudanças e adaptações em epistemologias, nas ciências em geral que em sua prática, na materialização dos conteúdos convergiram e aconteceram pela interdisciplinaridade nelas adotadas. Neste aspecto foram apresentadas e discutidas propostas que procuram justificar e embasar a adoção de práticas interdisciplinares direcionadas à Educação Escolar, sendo defendidas por enfoques teóricos, entre outros autores por uma perspectiva cujo processo de ensino e de aprendizagem necessita reconhecer que os conhecimentos científicos, técnicos e sociológicos se apresentam em um processo de profunda interação, contribuindo para que a formação educacional escolar seja inclusiva e emancipatória.

Parece importante ressaltar, como indicam Batista e Salvi (2006), que a dialogicidade entre os conhecimentos disciplinares e a perspectiva interdisciplinar, proposta como um movimento fluente e recorrente possibilitam ao desenvolvimento de novas formas de pensar e agir, pois, ao mesmo tempo em que se busca uma integração mais profunda para a compreensão dos conhecimentos, podem-se realizar estudos mais refinados, igualmente relevantes para a formação dos educandos.

Brasil (2016), Batista e Salvi (2006), Fourez et. al. (1997) e Santomé (1998).

A interdisciplinaridade agregou teorias discutirem, pensar e agir em diferentes sentidos, resgatando o caráter de interdependência e interatividade existente entre as coisas e as ideias portanto, visto que humanidade vive em meio à uma teia de interações, na qual todos estão interligados de algum modo, conectados em múltiplas plataformas de aprendizagem, nas quais não se usa somente a razão para aprender, mas também a intuição, as emoções, sensações, 
sentimentos e contextos multipluralizados em ambientes virtuais, dos nos quais a interdisciplinaridade está presente, e pode auxiliar aos educadores no trabalho

\section{REFERÊNCIAS}

BATISTA, I. L.; SALVI, R. F. Perspectiva pós-moderna e interdisciplinaridade educativa: pensamento complexo $e$ reconciliação integrativa. Ensaio, Belo Horizonte, v. 8, n. 2, p. 147-159, 2006.

BRASIL, Base Nacional Comum Curricular. A educação é a base. Brasília. MEC, 2016.

ENGLEBERT-LECOMPTE, V.; MATHY, P. Saber sobre nuestros saberes: um léxico epistemológico para lá enseñanza. Buenos Aires: Ediciones Colihue, 1997.

FOUREZ, G. Alfabetização científica y tecnológica: acerca de las finalidades de lá enseñanza de las ciencias. Buenos Aires: Ediciones Colihue, 1997.

GADOTTI, Moacir. A organização do trabalho na escola: alguns pressupostos. São Paulo: Ática, 1993. pedagógico criando articulação entre o ensinar e o aprender, materializando isso no seu fazer pedagógico

GADOTTI, Moacir e ROMÃO, José E. Autonomia da Escola. 6. ed. São Paulo: Cortez, (Guia da escola cidadã; v.1), 2004.

GOLDMAN, Lucien. Dialética e cultura. Rio de Janeiro: Paz e Terra, 1979.

JAPIASSU, $\mathrm{H}$. Interdisciplinaridade $e$ patologia do saber. Rio de Janeiro: Imago, 1976.

LEIS, Héctor Ricardo. Sobre o conceito de interdisciplinaridade. In: Cadernos de Pesquisa Interdisciplinar em Ciências Humanas. № 73, ago. 2005. Disponível em: $<$ https://periodicos.ufsc.br/index.php/cader nosdepesquisa/article/view/2176>. Acesso em: 23/05/2020.

KUHN, Thomas S. A estrutura das revoluções científicas. São Paulo: Perspectiva, 1989.

SANTOMÉ, Jurgo Torres. Globalização e interdisciplinaridade: o currículo integrado. Trad. Cláudia Schilling. Porto Alegre: Editora Artes Médicas Sul Ltda., 1998. 